ОЦЕНКА ОТКЛИКА ДРЕВОСТОЕВ СОСНЫ И ЕЛИ ЦЕНТРАЛЬНО-ЛЕСНОГО ГОСУДАРСТВЕННОГО ПРИРОДНОГО ЗАПОВЕДНИКА НА ТРАНСГРАНИЧНОЕ ЗАГРЯЗНЕНИЕ ВОЗДУХА МЕТОДАМИ МЕЖДУНАРОДНОЙ СОВМЕСТНОЙ ПРОГРАММЫ КОМПЛЕКСНОГО МОНИТОРИНГА

\author{
A.E. Kухma 1), 2)*, А.В. Пчелкин ${ }^{1)}$, А.М. Полешук ${ }^{3)}$
}

1) ФГБУН «Институт географии РАН»,

Россия, 119017, Москва, Старомонетный переулок, 29; avp1956@yandex.ru

2) ФГБУ «Институт глобального климата и экологии им. академика Ю.А.Израэля», Россия, 107258, Глебовская ул., 20Б; anna_koukhta@mail.ru

3) Государственный научный центр «Федеральный медицинский биофизический центр им. А.И. Бурназяна» ФМБА России,

Россия, 123182, Москва, ул. Живописная, 46; aleksaupsa@mail.ru

Реферат. В рамках выполнения Международной совместной программы комплексного мониторинга влияния загрязнения воздуха на экосистемы (МСП КМ), осуществляемой в рамках Конвенции о трансграничном загрязнении воздуха на большие расстояния Экономической комиссии ООН для Европы (ЕЭК ООН), на территории Центрально-Лесного государственного природного биосферного заповедника с 2009 г. проводилась оценка состояния крон древостоев. Для этого в разных типах леса (в сосняке сфагновом и ельнике черничном) в соответствии с методикой МСП КМ были заложено две пробных площади. Согласно методике, в августе-сентябре проводилась оценка таких показателей, как дефолиация и депигментация крон сосны и ели. Методом корреляционного анализа выявлялась зависимость рядов уровней дефолиации и депигментации изучаемых деревьев от уровней выпадений загрязняющих веществ, измеряемых на станции Совместной программы наблюдений и оценки переноса на большие расстояния загрязняющих воздух веществ в Европе (ЕМЕП), расположенной в заповеднике. Выявлены положительные зависимости состояния крон сосны, произрастающей на бедных торфяных почвах сфагновых болот, от выпадений химических соединений, в данном случае играющих роль удобрений (макро- и микроэлементов). Отмечено, что ельники, произрастающие на более богатых почвах, не показывают значимого отклика на поступление данных соединений, поскольку не испытывают дефицита питательных элементов. Уровень загрязнения по результатам измерений трансграничного загрязнения определяется как фоновый. Химические соединения, поступающие с трансграничным переносом атмосферных масс на изучаемую территорию в малых количествах, не оказывают значимого негативного воздействия на экосистемы заповедника.

Ключевые слова. Трансграничный перенос, ель европейская, сосна обыкновенная, дефолиация, депигментация, лесные экосистемы. 


\title{
THE EVALUATION OF THE PINE AND FIR STANDS RESPONSE TO TRANSBOUNDARY POLLUTION PRECIPITATION ON THE CENTRAL-FOREST RESERVE TERRITORY USING METHODS OF THE INTERNATIONAL COOPERATIVE PROGRAMME ON INTEGRATED MONITORING OF AIR POLLUTION EFFECTS ON ECOSYSTEMS

\author{
A.E. Kukhta 1), 2)* , A.V. Pchyolkin 1), A.M. Poleschook ${ }^{3)}$ \\ 1) Institute of Geography of RAS, \\ 29, Staromonetniy lane, 119017, Moscow, Russia; avp1956@yandex.ru; \\ 2) Yu.A. Izrael Institute of Global Climate and Ecology, \\ of Federal Medical Biological Agency, \\ 46, Zshipopisnaya str., 123182, Moscow, Russia; aleksaupsa@mail.ru
} 20b, Glebovskaya str., 107258, Moscow, Russia; anna_koukhta@mail.ru; \\ 3) State Research Center "Burnazyan Federal Medical Biophysical Center"
}

\begin{abstract}
In the framework of the International Cooperative Programme on Integrated Monitoring of Air Pollution Effects on Ecosystems (ICP IM) on the territory of the Central-Forest State Nature Biosphere Reserve since 2009 the forest stands crowns state was valuated. For this purpose, in different forest types (in sphagnum pine forest and in fir myrtillus forest) according to ICP IM Manual two sampling plots were founded. Such parameters as pine and fir crowns defoliation and depigmentation were estimated annually in August-September. The studied trees defoliation and depigmentation ranges dependence on pollution precipitation rate was identified using the correlation analysis method. The pollutants deposition values during a long period were measured on the Co-operative Programme for Monitoring and Evaluation of the Long-Range Transmissions of Air Pollutants in Europe (EMEP) station, based in the reserve. A positive relation between bog pine crowns state and pollutants deposition is defined. Pine stands grow on poor peat sphagnum bog soils, and the pollutants act as fertilizers (macro- and microelements). It is noted that fir stands growing on richer soils do not show any significant response to these chemical compounds intake because do not undergo trophic elements lack. Due to the transboundary pollution measurements results the studied region is identified as background. The chemical agents coming to the investigated territory with the transboundary atmosphere masses transport in small amounts do not cause any significant negative impact on the reserve ecosystems.

These are climatic factors (temperature and precipitation sums) changes that essentially affect the Scots pine and spruce fir photosynthesizing crown parts on the Central-Forest reserve sampling plots.
\end{abstract}

Keywords. Transboundary pollution, Scots pine, spruce fir, defoliation, depigmentation, forest ecosystems.

\section{Введение}

В условиях изменений климата и загрязнения окружающей среды все бо́льшую актуальность принимает задача оценки и прогнозирования состоя- 
ния лесных экосистем. Решению данной проблемы посвящен ряд международных программ мониторинга. В частности, в Российской Федерации выполняется Международная совместная программа комплексного мониторинга влияния загрязнения воздуха на экосистемы - MСП КМ (International Cooperative Programme on Integrated Monitoring of Air Pollution Effects on Ecosystems - ICP IM), выполняемая под эгидой Конвенции о трансграничном загрязнении воздуха на большие расстояния Экономической комиссии ООН для Европы (ЕЭК ООН). Основной целью данной программы является осуществление мониторинга состояния лесных экосистем, которые выполняют важную роль в уменьшении концентрации поллютантов (Пчелкин, 1999), и выявление связи их состояния с факторами окружающей среды с целью обеспечения научных основ для контроля выбросов. Наблюдения по этой программе проводятся на 60-ти станциях в Европе и Канаде. Данные получают по согласованным методикам, собранным в Руководстве по комплексному мониторингу.

В Российской Федерации МСП КМ осуществляет Национальный научнокоординационный центр (ННЦК), функционирующий в ФГБУ «Институт глобального климата и экологии Росгидромета и РАН». В обязанности ННКЦ входит сбор данных с сети стационаров программы, осуществление модельных расчетов на основе первичных данных, оценка результатов наблюдений по стране, а также представление результатов статистической обработки данных и своих заключений в международный центр данных. Стационары МСП КМ на территории РФ расположены на особо охраняемых природных территориях федерального и регионального значения.

Представленные в данной статье исследования проводились на стационаре МСП КМ, находящемся на территории Центрально-Лесного государственного природного биосферного заповедника (http://clgz.ru/?page_id=2803). По климатическому районированию Б.П. Алисова заповедник расположен в атлантикоконтинентальной лесной области, юго-западной подобласти умеренного пояса (Алисов, 1956). Территория характеризуется положительным балансом влаги: гидротермический коэффициент - 1.62; летом может снижаться до 0.5-0.9 (Климат. Центрально-Лесной заповедник; Нотов и др., 2016).

В составе фитоценозов заповедника доминирует южно-таёжный ельник. Сосняки занимают 10\% площади заповедника и представлены заболоченными фитоассоциациями с типичной бореальной флорой (Растительный мир. Центрально-Лесной заповедник).

Согласно данным, представленным рядом авторов (Бондарь и др., 1982; Гончарук и др., 1999), а также в Едином государственном реестре почвенных ресурсов в России и в Национальном атласе почв Российской Федерации, под зеленомошными, кисличными, чернично-кисличными и черничными ельниками в условиях избыточного увлажнения развиваются подзолистые, подзолисто-глееватые и реже подзолисто-глеевые почвы. Здесь накапливается грубый гумус; почвенные растворы обогащены сильными органическими кислотами. В сосняках сфагновых торфянистые и торфяные почвы характеризуются высокими влажностью и кислотностью, большим количеством закис- 
ных соединений, ненасыщенностью основаниями, малым содержанием зольных веществ и незначительной биологической активностью. Из-за крайне низкой трофности почвы древостой в таких местообитаниях характеризуется редкостойностью, низкорослостью и малым запасом древесины на единицу площади (Карпачевский, 2001).

Целью данной работы являлось определение отклика древостоев сосны и ели на пробных площадях, заложенных на территории ЦЛГЗ, на трансграничное загрязнение воздуха методами МСП КМ.

\section{Методы и материалы}

Для осуществления исследований согласно методике подпрограммы МСП КМ «Повреждение лесов», представленной в Руководстве по комплексному мониторингу, в разных типах леса 92 квартала заповедника были заложены две пробные площади (Manual ..., 2010; Руководство по комплексному мониторингу, 2013).

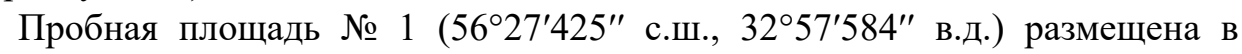
сосняке сфагновом (Pineta sphagnosa), характеризуемым IV-V классами бонитета. Сомкнутость составляет 0.1-0.2. В напочвенном покрове преобладают пушица Eriophorum vaginatum L. багульник Ledum palustre L., голубика Vaccinium uliginosum L., морошка Rubus chamaemorus L., а также два вида клюквы - Vaccinium oxycoccus L. и V. microcarpum Turcz. ex Rupr.

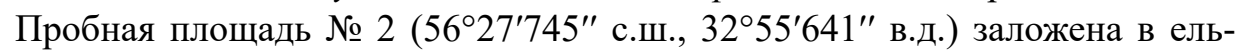
нике-зеленомошнике черничном с примесью березы (Piceeta myrtillosum). Древостой ели характеризуется II-III классами бонитета. Сомкнутость составляет 0.3-0.4. В составе напочвенного покрова доминируют черника Vaccinium myrtillus L., Geranium sp., злаки и мхи Pleurozium schreberi (Brid.) Mitt., Hylocomium splendens (Hedw.) B. S. G.

Пробная площадь № 1 заложена в межгрядовой котловине, на торфяных почвах. Пробная площадь № 2 расположена на моренной гряде и характеризуется подзолистой (глееватой) почвой.

Измерения проводились ежегодно по подпрограмме МСП КМ «Повреждение леса», в августе-сентябре, начиная с 2009 г. В работе рассмотрен ряд данных, полученных за 8 лет (в 2009-2015 гг).

Оценка повреждения древостоев проводилась по дефолиации и депигментации крон деревьев. С шагом 5\% экспертным методом регистрировались потеря хвои в изучаемой кроне в сравнении с воображаемым, полностью покрытым хвоей деревом той же породы, а также отклонение от обычной окраски живой хвои. Целью подобной оценки является ранняя количественная индикация изменений в фотосинтетически активной части деревьев.

В соответствии с методикой МСП КМ, на каждой пробной площади ежегодно измерялось по 20 деревьев. Таким образом, объем выборки в каждом году для каждого измеряемого параметра (дефолиации и депигментации) был равен двадцати. 
Для выявления зависимостей параметров состояния древостоев от уровней трансграничного загрязнения воздуха использовались результаты инструментальных измерений химического состава осадков, полученных в результате многолетних измерений по Совместной программе наблюдений и оценки переноса на большие расстояния загрязняющих воздух веществ в Европе (ЕМЕП) (Международная деятельность ..., ЕМЕП), выполняемой ФГБУ «ИГКЭ Росгидромета и РАН» (Международная деятельность ..., МСП КМ) на стационаре «Лесной», расположенном на территории ЦЛГЗ.

Зависимость динамик рядов значений дефолиации и депигментации деревьев от степени трансграничного загрязнения оценивались методом корреляционного анализа. Данные операции производились с использованием средств пакета Excel. Графические материалы также были разработаны с помощью указанного пакета. Значимость коэффициентов корреляции Пирсона проверялась по стандартной таблице (Большев, Смирнов, 1983).

\section{Результаты и дискуссия}

На основании полученных измерений для оценки состояния лесных насаждений под воздействием трансграничного загрязнения были подготовлены ряды значений дефолиации и депигментации (параметров откликов деревьев на загрязнение атмосферного воздуха и атмосферных осадков) древостоев (табл. 1). Значения дефолиации (DF) и депигментации (DP) сосны обыкновенной (P. sylvestris L.) и ели европейской (P. abies (L.) H. Karst.) за период наблюдений осреднялись для каждой пробной площади. В рядах измерений есть один пропуск (2011 год), заполненный средними арифметическими значениями параметров.

Таблица 1. Осредненные значения (в баллах) дефолиации $(D F)$ и депигментации $(D P)$ сосны обыкновенной (P. sylvestris) и ели европейской (P. abies) на пробных площадях №o 1 и 2 за период наблюдений

\begin{tabular}{|c|c|c|c|c|}
\hline \multicolumn{3}{|c|}{$\boldsymbol{P}$. sylvestris } & \multicolumn{2}{c|}{$\boldsymbol{P}$ abies } \\
\hline Годы & $\boldsymbol{D F}$ & $\boldsymbol{D P}$ & $\boldsymbol{D F}$ & $\boldsymbol{D P}$ \\
\hline 2009 & 22 & 14 & 24 & 19 \\
\hline 2010 & 22 & 14 & 24 & 19 \\
\hline 2011 & 28 & 21 & 25 & 18 \\
\hline 2012 & 26 & 21 & 30 & 18 \\
\hline 2013 & 49 & 19 & 26 & 11 \\
\hline 2014 & 24 & 23 & 24 & 19 \\
\hline 2015 & 30 & 22 & 27 & 21 \\
\hline
\end{tabular}

Как было указано выше, для выявления зависимостей параметров состояния древостоев от уровней трансграничного загрязнения воздуха использовались результаты инструментальных измерений химического состава осадков, полученных на стационаре «Лесной» по Совместной программе наблюдений и оценки переноса на большие расстояния загрязняющих воздух веществ в 
Европе (ЕМЕП, http://www.emep.int/). Методика отбора проб и анализа результатов представлена в (EMEP Manual ..., 1996). Результаты измерений размещены в базе данных ЕМЕП, ведущейся в ИГКЭ, и были предоставлены авторам руководством института. Значения «мокрых» выпадений за исследуемые годы суммировались по геофизическим годам (октябрь предыдущего года - сентябрь текущего года).

Таблица 2. Значения суммарных «мокрых» выпадений загрязняющих веществ

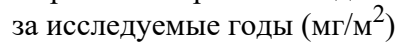

\begin{tabular}{|l|l|l|l|r|r|r|r|r|}
\hline Год & $\mathbf{S O}_{\mathbf{4}}{ }^{\mathbf{2}}-\mathbf{S}$ & $\mathbf{N O}_{\mathbf{3}}^{-} \mathbf{- N}$ & $\mathbf{N H}_{\mathbf{4}}{ }^{+}-\mathbf{N}$ & $\mathbf{N a}^{+}$ & $\mathbf{M g}^{\mathbf{+}}$ & $\mathbf{C a}^{\mathbf{2}}$ & $\mathbf{C l}^{-}$ & $\mathbf{K}^{+}$ \\
\hline 2009 & 298.85 & 178.02 & 257.56 & 450.32 & 38.21 & 201.44 & 590.18 & 297.27 \\
\hline 2010 & 307.44 & 237.44 & 398.30 & 215.07 & 40.41 & 279.65 & 290.33 & 195.67 \\
\hline 2011 & 235.80 & 155.31 & 234.65 & 84.03 & 22.41 & 178.33 & 168.81 & 80.93 \\
\hline 2012 & 259.26 & 213.09 & 330.80 & 127.87 & 32.85 & 275.55 & 280.23 & 125.36 \\
\hline 2013 & 259.04 & 219.56 & 205.48 & 98.11 & 29.50 & 273.34 & 180.44 & 89.74 \\
\hline 2014 & 250.49 & 181.47 & 256.45 & 152.74 & 25.30 & 215.80 & 254.65 & 140.17 \\
\hline
\end{tabular}

Для выявления связи состояния крон деревьев и поступления загрязняющих веществ в осадках был проведен корреляционный анализ рядов измерений параметров состояния древостоев (дефолиации $(D F)$ и депигментации $(D P))$ сосны (P. sylvestris), ели (P. abies) и уровней суммарных «мокрых» выпадений на двух пробных площадях. Результаты этого анализа представлены в табл. 3. Значимые коэффициенты корреляции выделены жирным шрифтом. Далее в работе будут рассматриваться только значимые зависимости.

Таблица 3. Коэффициенты корреляции $(R)$, характеризующие зависимость дефолиации и депигментации сосны и ели от содержания химических соединений в осадках (уровень достоверности 0.05)

\begin{tabular}{|c|c|c|c|c|}
\hline \multirow{2}{*}{} & \multicolumn{2}{|c|}{ P. sylvestris } & \multicolumn{2}{c|}{ P. abies } \\
\cline { 2 - 5 } & $\mathbf{D F}$ & $\mathbf{D P}$ & $\mathbf{D F}$ & DP \\
\hline $\mathrm{SO}_{4}{ }^{2-}-\mathrm{S}$ & -0.34 & $\mathbf{- 0 . 9 3}$ & -0.42 & -0.04 \\
\hline $\mathrm{NO}_{3}{ }^{-}-\mathrm{N}$ & 0.21 & -0.38 & 0.14 & -0.39 \\
\hline $\mathrm{NH}_{4}{ }^{+}-\mathrm{N}$ & $\mathbf{- 0 . 5 9}$ & -0.35 & 0.18 & 0.49 \\
\hline $\mathrm{Na}^{+}$ & -0.47 & $\mathbf{- 0 . 7 0}$ & -0.34 & 0.35 \\
\hline $\mathrm{Mg}^{2+}$ & -0.28 & $\mathbf{- 0 . 7 0}$ & 0.06 & 0.27 \\
\hline $\mathrm{Ca}^{2+}$ & 0.29 & 0.00 & 0.52 & -0.09 \\
\hline $\mathrm{Cl}^{-}$ & -0.50 & $\mathbf{- 0 . 6 6}$ & -0.24 & 0.30 \\
\hline $\mathrm{K}^{+}$ & -0.56 & $\mathbf{- 0 . 7 5}$ & -0.36 & 0.38 \\
\hline
\end{tabular}

Если рассмотреть представленные в табл. 3 значимые коэффициенты корреляции зависимостей дефолиации и депигментации сосны и ели от выпадений химических соединений, обнаруживаются следующие результаты. 
Зарегистрирована отрицательная корреляция рядов дефолиации сосны и суммарных выпадений $\mathrm{NH}_{4}{ }^{+}-\mathrm{N}(R=-0.59)$. Кроме того, отмечены отрицательные корреляции рядов депигментации сосны и выпадений $\mathrm{SO}_{4}{ }^{2-}-\mathrm{S}(R=-0.93)$, натрия $(R=-0.70)$, магния $(R=-0.70)$, хлора $(R=-0.66)$ и калия $(R=-0.75)$. Значимых результатов для ели не зарегистрировано.

Как было отмечено выше, наблюдения на территории ЦЛГЗ были начаты в 2009 г. Таким образом, в нашем распоряжении имеется короткий (7 лет) ряд измерений, что объясняет малое количество значимых коэффициентов корреляций искомых зависимостей. Тем не менее, полученные величины позволяют выделить ряд закономерностей.

Выпадения азота в форме $\mathrm{NH}_{4}^{+}$характеризуются значимым отрицательным коэффициентом корреляции для дефолиации сосны $(R=-0.59)$. Указанная зависимость отражает снижение уровня потери хвои при поступлении азота в данной форме.

Коэффициенты корреляции рядов параметров депигментации и выпадений серы для сосны отрицательные $(R=-0.93)$. Данный результат представлен на рис. 1. Очевидно, полученная закономерность означает, что увеличение уровня выпадений сульфатов снижает депигментацию хвои и улучшает состояние ассимиляционного аппарата данной породы. Отмечено значимое снижение депигментации при увеличении уровня выпадений натрия $(R=-0.70)$, магния $(R=-0.70)$ и хлоридов $(R=-0.66)$. Выпадения калия $(R=-0.75)$ также находятся в обратной зависимости с рядами значений депигментации крон сосны. Сходные результаты оценки сопряженности трансграничных выпадений загрязняющих веществ и состояния лесных биогеоценозов были получены ранее в ходе выполнения МСП КМ в ЦЛГЗ (Pozdnyakova et al., 2017).

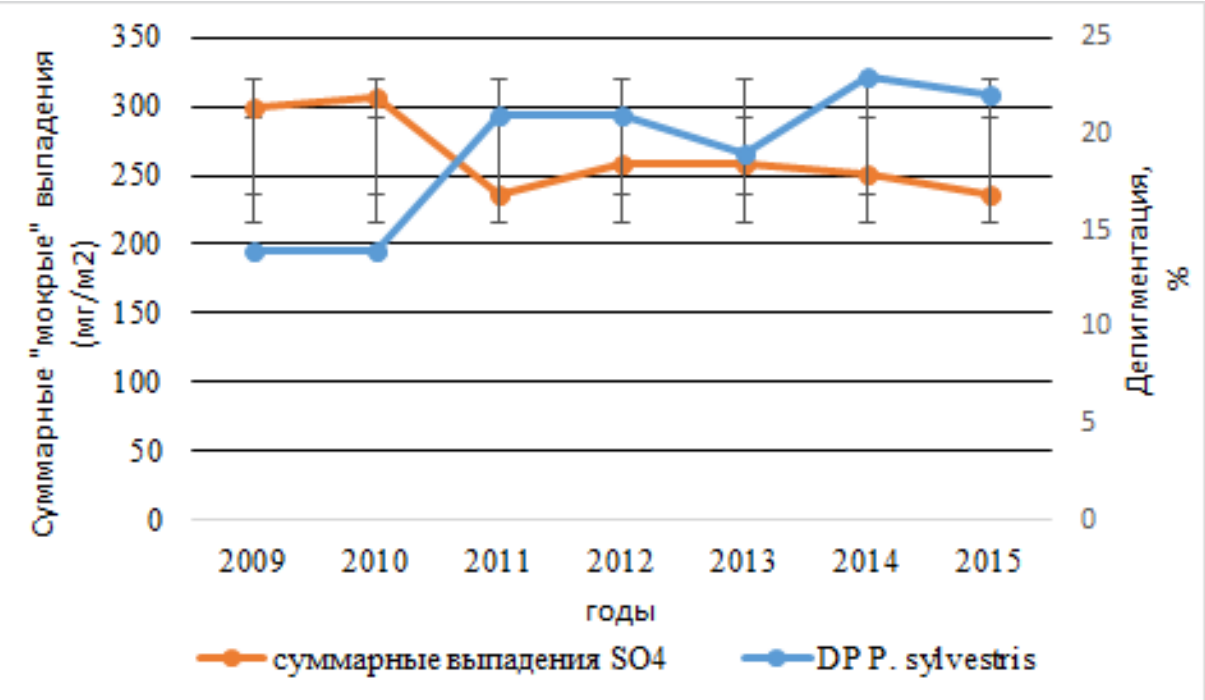

Рисунок 1. Зависимость динамики депигментации (DP) сосны от суммарных выпадений сульфатов

Полученные результаты анализа объясняются, по нашему мнению, следующими причинами. Сосняк на пробной площади № 1 расположен на торфя- 
ных (болотных) почвах, которые формируются на сфагновых верховых болотах. Подобные почвы образуются под моховыми сообществами и/или сосновыми лесами, при постоянном избыточном переувлажнении. В них накапливается значительное количество неразложившегося органического вещества. Растительные остатки разлагаются здесь не полностью, при этом нет поступления кальция, калия, фосфора. Торфяная масса имеет кислую реакцию, вследствие чего элементы питания в торфе переходят в недоступные для растений формы. Такие почвы бедны фосфором, калием, магнием, микроэлементами, вследствие чего растительный покров характеризуется низким уровнем биоразнообразия и специфическим видовым составом. При культивировании культурных форм растений на подобных почвах требуется внесение удобрений.

Ельник на пробной площади № 2 расположен на подзолистых (глееватых) почвах. Подобные почвы формируются на слабодренированных равнинах, в понижениях, под южнотаежными лесами, к которым относится территория ЦЛГЗ. Подзолистые глееватые почвы характеризуются сильнокислой реакцией и низким содержанием гумуса. Являясь одним из наиболее ограниченных в плане содержания элементов питания типов почв, торфяные болотные почвы беднее подзолистых, и болотная растительность в большей степени ограничена ресурсами, чем бореальные ельники. Следовательно, сосняк на пробной площади № 1, произрастающий на болоте, в сравнении с ельником на пробной площади № 2, испытывает бо́льшую нехватку макро- и микроэлементов. К макроэлементам относятся азот, фосфор, калий, кальций, сера, магний, железо; к микроэлементам - натрий, хлор, кремний, бор. Указанные элементы необходимы для нормального развития растений; их нехватка вызывает опадение и пожелтение листвы или хвои (дефолиацию и депигментацию), а также карликовость форм (Вильдфлуш и др., 2001). Именно элементов питания (макро- и микроэлементов) не хватает древостоям на торфяных почвах ЦЛГЗ. В то же время почвы, на которых произрастают бореальные ельники, хоть и не является действительно плодородными, содержат больше необходимых для растений ресурсов.

Трансграничное поступление химических соединений, измеряемое в ЦЛГЗ на станции ЕМЕП, характеризуется низким, незначительным уровнем. Указанный уровень выпадений химических соединений характерен для районов, которые как в России, так и в мире считаются фоновыми.

В условиях нехватки элементов питания на торфяных почвах в сфагновых сосняках заповедника указанные химические соединения, попадающие в почвы с осадками, играют роль удобрений, улучшая состояние растений и, в частности, качество крон деревьев. Подобный вывод подтверждается результатами корреляционного анализа рядов параметров дефолиации и депигментации сосны и суммарных выпадений химических веществ. Наблюдается значимое положительное воздействие поступления азота, серы, натрия, магния, хлора и калия на состояние крон сосняка.

В то же время в ельниках на подзолистых, более обеспеченных элементами питания почвах, не обнаружено значимых зависимостей от поступлений 
этих химических соединений. Вероятно, деревья получают достаточно ресурсов из почвы, поэтому корреляционный анализ не отразил зависимостей дефолиации и депигментации ели от выпадений дополнительных макро- и микроэлементов. При этом количество поступающих с трансграничным атмосферным переносом химических агентов столь мало, что не оказывает и значимого отрицательного воздействия на состояние крон.

Отсутствие значимого отклика некоторых фитоассоциаций на трансграничное загрязнение отмечено в работах как отечественных (Pozdnyakova et al., 2017), так и зарубежных авторов (Anchukaitis et al., 2017; Lundin et al., 2016), принимающих участие в выполнение международных программ фонового мониторинга, в том числе ЕМЕП и МСП КМ.

Между тем, целый ряд исследований отмечает значимое воздействие климатических параметров на состояние растительности, в том числе и крон деревьев. Климатический сигнал в рядах параметров прироста деревьев выявляется как на глобальном уровне (Schwalm et al., 2017), так и в региональном масштабе. В частности, проведенные ранее на территории ЦЛГЗ исследования показывают, что дефолиация и депигментация сосны и ели на территории заповедника является откликом не на химическое загрязнение, а, в значительной степени, на воздействие изменчивости климатических параметров - рядов температуры и сумм осадков (Позднякова и др., 2014; Кухта и др., 2014; Кухта, 2009, 2011; Обзор состояния ...., 2017; Румянцев и др., 2016; Pozdnyakova et al., 2016). Следовательно, в дальнейшем при осуществлении мониторинга лесных экосистем Европейской части РФ в условиях изменения климатической системы Земли следует учитывать данные закономерности, что позволит точнее прогнозировать динамику состояния биогеоценозов региона.

\section{Заключение}

В результате ежегодного осуществления исследований в рамках Международной совместной программы комплексного мониторинга (МСП КМ) на территории ЦЛГЗ было установлено, что химические соединения поступают с атмосферным переносом на пробные площади в малых концентрациях; данный район является фоновым и служит эталоном ненарушенных лесных экосистем. Полученные в результате выполнения МСП КМ результаты оценки состояния древостоев заповедника показывают, что выпадающие с осадками химические вещества оказывают положительное воздействие на состояние сосняков, которые произрастают на бедных торфяных почвах на сфагновых болотах. В такой ситуации выпадения химических агентов играют роль удобрений (макро- и микроэлементов). В то же время ельники, приуроченные к подзолистым, более богатым почвам, не показывают значимого отклика на поступление этих соединений, поскольку не испытывают подобного дефицита питательных элементов. При этом химические вещества, поступающие с трансграничным переносом на изучаемую территорию в малых количествах, не оказывают значимого негативного воздействия на экосистемы заповедника. 


\section{Список литературы}

Алисов Б.П. 1956. Климат СССР. - М., Изд-во Моск. ун-та., 128 с.

Атлас земель сельскохозяйственного назначения. Единый государственный реестр почв России. - Электронный ресурс. URL: http://atlas.mcx.ru/ materials/egrpr/content/soils/soil054.html (дата обращения 1 марта 2018).

Большев Л. Н., Смирнов Н. В. 1983. Таблицы математической статистики. - М., Наука, 415 с.

Бондарь В.И., Карпачевский Л.О., Строганова М.Н. и др. 1982. Генетические горизонты подзолистых почв лесных биогеоценозов. - В кн.: Комплексные биогеоценотические исследования в Центрально-Лесном заповеднике за 50 лет. Тезисы докладов научной конференции 27-29 июля 1982 года. - М., с. 25-27.

Вильдфлуш И.Р., Кукреш С.П., Ионас В.А. и др. 2001. Агрохимия. - Учебник, 2-е изд., доп. и перераб. - Минск, Ураджай, 488 с.

Гончарук Н.Ю., Желтухина В.И., Карпачевский Л.О. и др. 1999. Формы антропогенной динамики южнотаежных лесных сообществ. Типы и формы динамики лесов заповедного массива. - В кн.: Сукцессионные процессы в заповедниках России и проблемы сохранения биологического разнообразия. Глава 6. Центрально-Лесной биосферный заповедник. - СПб., ВБО, с. 396-417.

Карпачевский Л.О. 2001. Динамика свойств почв. - М., ГЕОС. - Электронный pecypc. URL: http://download1.libgen.io/ads.php?md5=E2788B7D 4571504907B88905B0746D9F (дата обращения 2 марта 2018).

Климат. Центрально-Лесной заповедник. - Электронный ресурс. URL: http://clgz.ru/?page_id=2803 (дата обращения 2 марта 2018).

Кухта А.Е. 2009. Влияние температуры и осадков на годичный линейный прирост сосны обыкновенной на берегах Кандалакшского залива. - Лесной вестник/Forestry Bulletin, № 1, с. 61-66.

Кухта А.Е. 2011. Климатические и локальные факторы изменчивости параметров приростов сосны обыкновенной трех особо охраняемых территорий Севера России. - Лесной вестник/Forestry Bulletin, № 4, с. 221-226.

Кухта А.Е., Румянцев Д.Е., Пучинская Д.В. 2014. Влияние климатических факторов на радиальный и линейный прирост сосны обыкновенной в условиях заповедника «Кивач». - Лесной вестник/Forestry Bulletin, № 5, с. 88-91.

Международная деятельность ФГБУ «Институт Глобального Климата и Экологии Росгидромета и РАН». ЕMЕП. - Электронный ресурс. URL: http:// www.igce.ru/page/emep (дата обращения 1 марта 2018).

Международная деятельность ФГБУ «Институт Глобального Климата и Экологии Росгидромета и РАН». МСП КМ (ICP IM). - Электронный ресурс. URL: http://www.igce.ru/page/icp_im (дата обращения 3 марта 2018). 
Национальный атлас почв Российской Федерации. Дерново-подзолы. Дерново-подзолисто-глеевые почвы. - Электронный ресурс. URL: https:// soilatlas.ru/110-111 (дата обращения 5 марта 2018).

Нотов А.А., Гимельбрант Д.Е, Степанчикова И.С., Волков В.П. 2016. Лишайники Центрально-Лесного государственного природного биосферного заповедника. - Тверь, Твер. гос. ун-т, 332 с.

Обзор состояния и загрязнения окружающей среды в Российской Федерации за 2016 г. 2017. - Москва, Росгидромет, 217 с.

Позднякова Е.А., Пчелкина Т.А., Кухта А.Е. 2014. Оценка воздействия климатических факторов на древостои побережья Белого моря методом Международной совместной программы комплексного мониторинга. Использование и охрана природных ресурсов в России, № 2 (134), с. 31-37.

Пчелкин А.В. 1999. Фильтрующая роль лесонасаждений на примере Московской кольцевой автомобильной дороги (МКАД) и национального парка «Лосиный остров». - Проблемы управления качеством окружающей среды (IV Междун. конф., сборник докладов). - М., Изд-во Прима Пресс, с. 225-232.

Растительный мир. Центрально-Лесной заповедник. - Электронный pecypc. URL: http://clgz.ru/?page_id=2896 (дата обращения 2 марта 2018).

Руководство по комплексному мониторингу. 2013. - М., ФГБУ «ИГКЭ Росгидромета и РАН». - Электронный ресурс. URL: http://downloads.igce.ru/ publications/ICP_IM_Manuals/Manual_rus_04122013.pdf, 153 с. (дата обращения 8 марта 2018).

Румянцев Д.Е., Кухта А.Е., Пучинская Д.В. 2016. Климатический сигнал засух в хронологии ели из кисличного типа леса Центрально-Лесного заповедника. - Лесной вестник/Forestry Bulletin, т. 20, № 2, с. 36-43.

Anchukaitis K.J., Wilson R., Briffa K.R. et al. 2017. Last millennium Northern Hemisphere summer temperature from tree rings: Part II, spatially resolved reconstructions. - Quaternary Science Reviews, vol. 163, pp. 1-22.

EMEP manual for sampling and chemical analysis. 1996. - EMEP/CCC-Report 1/95, NILU, Kjeller, Norway. Available at: https://www.nilu.no/projects/ccc/ manual/index.html (accessed 5 March 2018).

International Cooperative Programme on Integrated Monitoring of Air Pollution Effects on Ecosystems (ICP IM). - Available at: http://www.syke.fi/nature/icpim/ (accessed 1 March 2018).

Lundin L., Lofgren S., Bovin K. et al. 2016. Report on National ICP IM activities in Sweden 2014-2015. - Reports of the Finnish Environment Institute, vol. 29, pp. 65-69.

Manual for Integrated Monitoring. 2010 - Available at: http://www.syke.fi/enUS/Research_Development/Ecosystem_services/Monitoring/Integrated_Monitoring/Manual_for_Integrated_Monitoring (accessed 1 March 2018). 
Pozdnyakova E., Konkova E., Koukhta A., Gromov S. 2017. Simultaneous analysis of coniferous forest state parameters and atmospheric deposition data series by ICP IM and EMEP in Central Forest Nature Reserve / Report on National ICP IM activities in Russia. - Reports of the Finnish Environment Institute, vol. 24, pp. 50-53.

Pozdnyakova E.A., Volkova G.L., Kukhta A.E., Volkov A.A. 2016. Effect of temperature and precipitation on the annual height increment of Scots pine on the Kandalaksha gulf coast and ICP IM SITE RU16. - Reports of the Finnish Environment Institute, vol. 29, pp. 62-64.

Schwalm C.R., Anderegg W.R.L., Michhalak A.M. et al. 2017. Global patterns of drought recovery. - Nature, vol. 548, pp. 202-217. Doi:10.1038/nature23021.

\section{References}

Alisov B.P. 1956. Klimat SSSR [The climate of the USSR]. Moscow, 128 p.

Bol'shev L.N., Smirnov N.V. 1983. Tablitsy matematicheskoi statistiki [Tables of mathematical statistics]. Moscow, $415 \mathrm{p}$.

Bondar' V.I., Karpachevskyi L.O., Stroganova M.N. et al. 1982. Geneticheskie gorizonty podzolistyh pochv lesnyh biotsenozov [Genetic horizons of podzolic soils of forest biogeocenoses]. Kompleksnye biogeotsenoticheskie issledovaniya $v$ Tsentral'no-Lesnom zapovednike za 50 let. Tezisy dokladov nauchnoi konferentsii 27-29 iyulya 1982 goda [In: Integrated Biogeocenotic Studies in the Central Forest Reserve for 50 years. Abstracts of scientific conferences on July 27-29, 1982]. Moscow, pp. 25-27.

Vil'dflush I.R., Kukresh S.P., Ionas V.A. 2001. Agrokhimiya [Agrochemistry]. Minsk, 488 p.

Goncharuk N.Yu., Zsheltuhina V.I., Karpachevskyi L.O. i dr. 1999. Formy antropogennoi dinamiki yuzshnotaezshnih lesnyh soobschestv. Tipy i formy dinamiki lesov zapovednogo massiva [Forms of the anthropogenic dynamics of south-taiga forest communities. Types and forms of forest dynamics of the protected massif]. $V$ kn.: Suktsessionnye protsessy $v$ zapovednikah Rossii $i$ problemy sohraneniya biologicheskogo raznoobraziya. Glava 6. Tsentral'noLesnoi biosfernyi zapovednik [In the book: Succession Processes in Russian Reserves and Problems of Conservation of Biological Diversity. Chapter 6. Central Forest Biosphere Reserve]. St. Petersburg, pp. 396-417.

Atlas zemel' sel'skokhozyaistvennogo naznacheniya. Edinyi gosudarstvennyi reestr pochvennykh resursov $v$ Rossii [Atlas of agricultural land. Unified State Register of Soils of Russia]. Available at: http://atlas.mcx.ru/materials/egrpr/ content/soils/soil054.html (accessed 1 March 2018)

Mezhdunarodnaya deyatel'nost' FGBU «Institut global'nogo klimata i ekologii Rosgidrometa $i$ RAN». EMEP [International activities of the Federal State Budgetary Institution "Institute of Global Climate and Ecology of Roshydromet 
and the Russian Academy of Sciences". EMEP]. Available at: http:/www.igce.ru/ page/emep (accessed 1 March 2018).

Mezhdunarodnaya deyatel'nost' FGBU «Institut global'nogo klimata i ekologii Rosgidrometa $i$ RAN». MSP KM [International activities of the Federal State Budgetary Institution "Institute of Global Climate and Ecology of Roshydromet and the Russian Academy of Sciences". ICP IM]. Available at: http:/www.igce.ru/ page/icp_im (accessed 3 March 2018).

Natsional'nyi atlas pochv Rossiiskoi Federatsii. Dernovo-podzoly. Dernovopodzolisto-gleevye pochvy [National Atlas of Soils of the Russian Federation Sodpodzols. Sod-podzolic-gley soils]. Available at: https://soilatlas.ru/110-111 (accessed 5 March 2018).

Karpachevsky L.O. 2001. Dinamika svoistv pochv [The dynamics of soil properties]. Moscow. Available at: http://download1.libgen.io/ads.php?md5= E2788B7D4571504907B88905B0746D9F (accessed 1 March 2018).

Klimat. Tzentral'no-Lesnoy zapovednik [Climate. Central Forest Reserve]. Available at: http://clgz.ru/?page_id=2803 (accessed 2 March 2018).

Kukhta A.E. 2009. Vliyanie temperatury i osadkov na godichnyi lineinyi prirost sosny obyknovennoi na beregakh Kandalakshskogo zaliva [Influence of temperature and precipitation on annual linear growth of Scots pine on the banks of Kandalaksha Bay]. Lesnoi vestnik - Forestry Bulletin, no. 1, pp. 61-66.

Kukhta A.E. 2011. Klimaticheskie i lokal'nye faktory izmenchivosti parametrov prirostov sosny obyknovennoi trekh osobo okhranyaemykh territorii Severa Rossii [Climatic and local factors of variability of parameters of increments of pine of ordinary three especially protected territories of the North of Russia]. Lesnoi vestnik-Forestry Bulletin, no. 4, pp. 221-226.

Kukhta A.E., Rumyantsev D.E., Puchinskaya D.V. 2014. Vliyanie klimaticheskikh faktorov na radial'nyi i lineinyi prirost sosny obyknovennoi $\mathrm{v}$ usloviyakh zapovednika "Kivach" [The influence of climatic factors on the radial and linear growth of common pine in the reserve "Kivach"]. Lesnoi vestnik Forestry Bulletin, no. 5, pp. 88-91.

Notov A.A., Gimelbrant D.E., Stepanchikova I.S., Volkov V.P. 2016. Lishainiki Tzentral'no-Lesnogo gosudarstvennogo prirodnogo zapovednika [Lichens of the Central Forest State Natural Biosphere Reserve]. Tver', 332 p.

Pozdnyakova E.A., Pchelkina T.A., Kukhta A.E. 2014. Otsenka vozdeistviya klimaticheskikh faktorov na drevostoi poberezh'ya Belogo morya metodom Mezhdunarodnoi sovmestnoi programmy kompleksnogo monitoringa [Assessment of the impact of climatic factors on the stands of the White sea coast by the method of the International joint program of complex monitoring]. Ispol'zovanie i okhrana prirodnykh resursov $v$ Rossii [Use and protection of natural resources in Russia], no. 2 (134), pp. 31-37.

Pchelkin A.V. 1999. Fil'truyushchaya rol' lesonasazhdenii na primere Moskovs- 
koi kol'tsevoi avtomobil'noi dorogi (MKAD) i natsional'nogo parka "Losinyi ostrov" [The filtering role of planted forests on the example of the Moscow ring road (MKAD) and "Losiny Ostrov" national Park]. Chetvertaya mezhdunarodnaya konferentsiya "Problemy upravleniya kachestvom okruzhayushchey sredy» $\left[4^{\text {th }}\right.$ International conference «Environmental quality management problems»]. Moscow, pp. 225-232.

Rastitel'ny mir. Tzentral'no-Lesnoy zapovednik [Vegetable world. Central Forest Reserve]. Available at: http://clgz.ru/?page_id=2896 (accessed 2 March 2018).

Rukovodstvo po kompleksnomu monitoringu [Manual for integrated monitoring]. 2013. Moscow. Available at: http://downloads.igce.ru/publications/ ICP_IM_Manuals/Manual_rus_04122013.pdf (accessed 8 March 2018).

Rumyantsev D.E., Kukhta A.E., Puchinskaya D.V. 2016. Klimaticheskii signal zasukh v khronologii eli iz kislichnogo tipa lesa Tsentral'no-Lesnogo zapovednika [Climatic signal of droughts in the chronology of sorrel spruce forest type Central Forest reserve]. Lesnoi vestnik - Forestry Bulletin, vol. 20, no. 2, pp. 36-43.

Obzor sostoyaniya $i$ zagryazneniya okruzhayushchey sredy $v$ Rossiyskoy Federatsii za $2016 \mathrm{~g}$. [Overview of the state and environmental pollution in the Russian Federation for 2016]. 2017. Moscow, 217 p.

Anchukaitis K.J., Wilson R., Briffa K.R. et al. 2017. Last millennium Northern Hemisphere summer temperature from tree rings: Part II, spatially resolved reconstructions. - Quaternary Science Reviews, vol. 163, pp. 1-22.

EMEP manual for sampling and chemical analysis. 1996. - EMEP/CCC-Report 1/95, NILU, Kjeller, Norway. Available at: https:/www.nilu.no/projects/ccc/ manual/index.html (accessed 5 March 2018).

International Cooperative Programme on Integrated Monitoring of Air Pollution Effects on Ecosystems (ICP IM). - Available at: http://www.syke.fi/nature/icpim/ (accessed 1 March 2018).

Lundin L., Lofgren S., Bovin K. et al. 2016. Report on National ICP IM activities in Sweden 2014-2015. - Reports of the Finnish Environment Institute, vol. 29 , pp. 65-69.

Manual for Integrated Monitoring. 2010. - Available at: http://www.syke.fi/enUS/Research_Development/Ecosystem_services/Monitoring/Integrated_Monitoring/Manual_for_Integrated_Monitoring (accessed 1 March 2018). Pozdnyakova E., Konkova E., Koukhta A., Gromov S. 2017. Simultaneous analysis of coniferous forest state parameters and atmospheric deposition data series by ICP IM and EMEP in Central Forest Nature Reserve / Report on National ICP IM activities in Russia. - Reports of the Finnish Environment Institute, vol. 24, pp. 50-53.

Pozdnyakova E.A., Volkova G.L., Kukhta A.E., Volkov A.A. 2016. Effect of temperature and precipitation on the annual height increment of Scots pine on the 
Kandalaksha gulf coast and ICP IM SITE RU16. - Reports of the Finnish Environment Institute, vol. 29, pp. 62-64.

Schwalm C.R., Anderegg W.R.L., Michhalak A.M. et al. 2017. Global patterns of drought recovery. - Nature, vol. 548, pp. 202-217. Doi:10.1038/nature23021. 